\title{
EL OBSERVATORIO DEL NOROESTE IBÉRICO: EMPRENDIMIENTO SOCIAL PARA UN TERRITORIO SOSTENIBLE
}

\author{
The Northwest Iberian Observatory: Social \\ Entrepreneurship for a Sustainable Territory \\ O observatório do noroeste ibérico: empreendedorismo \\ social para um território sustentável
}

\author{
Jorge VEGA NÚÑEZ \\ jvega@ponferrada.uned.es \\ José Luis CALVO GONZÁLEZ \\ Director de la Cátedra de Turismo Sostenible y Desarrollo Local \\ jcalvo@cee.uned.es
}

Director del Consorcio Público Universitario de la UNED en la provincia de León

Fecha de recepción: 14/09/2020

Fecha de aceptación: 7/11/2020

\begin{abstract}
RESUMEN: El Observatorio Territorial del Noroeste, surgido como acuerdo de colaboración entre la UNED, la Universidad de León y la Fundación Ciudad de la Energía, se puso en marcha en 2011 y con un enfoque bottom up ha venido generando actividades basadas en el conocimiento que, centradas en la innovación y las nuevas tecnologías, han contribuido a crear servicios de valor en el territorio. De esta forma, sobre la base de la participación, los agentes sociales, económicos, ambientales y políticos de la Comarca de El Bierzo como laboratorio del Noroeste vienen colaborando en una Red de Emprendimiento Social que trata de lograr un territorio más sostenible.
\end{abstract}


JORGE VEGA NÚÑEZ Y JOSÉ LUIS CALVO GONZÁLEZ

EL OBSERVATORIO DEL NOROESTE IBÉRICO: EMPRENDIMIENTO SOCIAL PARA UN TERRITORIO SOSTENIBLE

Palabras clave: Emprendimiento; Desarrollo Local; Gobernanza; Redes Sociales; TICs.

ABSTRACT: The Northwest Territorial Observatory, which emerged as a collaboration agreement between UNED, the University of León and the Ciudad de la Energía Foundation, was launched in 2011 and with a bottom-up approach has been generating activities based on knowledge that, focused on in innovation and new technologies, they have contributed to creating valuable services in the territory. In this way, on the basis of participation, the social, economic, environmental and political agents of the El Bierzo region as a Northwest laboratory have been collaborating in a Social Entrepreneurship Network that tries to achieve a more sustainable territory.

Key words: Entrepreneurship; Local Development; Governance; Social Networks; ICTs.

RESUMO: O Observatório Territorial do Noroeste, surgiu como um convênio de colaboração entre a UNED, a Universidade de León e a Fundação Ciudad de la Energía, foi lançado em 2011 e com uma abordagem ascendente vem gerando atividades baseadas no conhecimento que, com foco em em inovação e novas tecnologias, têm contribuído para a criação de serviços valiosos no território. Desta forma, a partir da participação, os agentes sociais, econômicos, ambientais e políticos da região de El Bierzo como laboratório do Noroeste têm colaborado em uma Rede de Empreendedorismo Social que busca alcançar um território mais sustentável.

Palavras chave: Empreendedorismo; Desenvolvimento Local; Governança; Redes Sociais; TICs.

I. INTRODUCCIÓN: TERRITORIOS CON DESEQUILIBRIOS SOCIOECONÓMICOS Y EN VÍAS DE DESPOBLAMIENTO

En noviembre de 2018 cerró la última mina de carbón en el Bierzo, después de un siglo en el que dicha actividad conformase una cultura específica en la Comarca.

Pero en realidad esta noticia no suponía ninguna sorpresa. En 2004 varios investigadores de la UNED publicábamos «¿Después del Carbón qué?, estudio socioeconómico de una cuenca minera de Castilla y León " ${ }^{1}$, que ya reflejaba que el sub-sector energía y en concreto la minería de la antracita había visto reducirse el empleo en la cuenca Fabero-Sil en un 85\% en los 35 años previos, y que ponía de relieve la cuestión de las prejubilaciones y su difícil «reconversión» a otras

1. http://observatorionoroeste.es/index.php/territorio/ 
JORGE VEGA NÚÑEZ Y JOSÉ LUIS CALVO GONZÁLEZ

EL OBSERVATORIO DEL NOROESTE IBÉRICO: EMPRENDIMIENTO SOCIAL PARA UN TERRITORIO SOSTENIBLE

actividades con el consecuente éxodo a otras zonas, dando lugar a la cada vez más preocupante reducción de población en los municipios mineros.

En definitiva, se trata de zonas en las que persiste un elevado nivel de dependencia económica respecto de la minería del carbón, como consecuencia de la marcada especialización productiva (monocultivo) prolongada en el tiempo, y a pesar de los esfuerzos realizados por los diversos Planes del Carbón para fomentar otras actividades productivas. Estas zonas presentan un progresivo declive socioeconómico, puesto que la destrucción de empleo derivada de la reestructuración de la minería del carbón ha llevado a la despoblación de muchos municipios, observándose una escasez de proyectos que apoyen la reconversión hacia actividades rentables (especialmente en ámbitos tecnológicos).

El complicado panorama que hemos descrito hasta aquí justifica la necesidad de diseñar y consensuar entre todos los agentes públicos y privados implicados un modelo de desarrollo que permita la reactivación de estos territorios que sufren desequilibrios socioeconómicos y se encuentran en vías de despoblamiento, es decir, «un relato» para el fututo de El Bierzo.

La actual situación provocada por el COVID-19 puede suponer una oportunidad para El Bierzo, ya que podría servir para que muchos residentes en grandes ciudades se replanteen la oportunidad de instalarse en entornos menos masificados y, por ende, potencialmente más seguros. Pero para aprovecharla, el modelo socioeconómico que debe consensuarse ha de cumplir dos condiciones:

En primer lugar, ha de ser compatible con los Objetivos de Desarrollo Sostenible de la ONU y que la Unión Europea ha hecho suyos. En este sentido, proponemos un modelo productivo de Economía Circular donde los bienes se producen, se consumen, se reciclan y se vuelven a consumir, cerrando el ciclo.

En segundo lugar, resulta imprescindible plantear un modelo de desarrollo perfectamente adaptado al paradigma económico actual caracterizado por una Economía del Conocimiento ${ }^{2}$ soportada tecnológicamente en la Cuarta revolución Industrial que representa nuevas formas en que la tecnología se integra en las sociedades y está marcada por los avances tecnológicos emergentes en varios campos ${ }^{3}$.

Estas tecnologías, como hemos tenido ocasión de comprobar en este confinamiento, permiten conectar a miles de millones de personas a la web, mejorar drásticamente la eficiencia de las empresas y organizaciones y ayudar a regenerar el entorno natural a través de una mejor gestión de activos. En este sentido, la UNED con más de 200 sedes a nivel nacional que constituyen una Red de Servicios

2. En nuestro trabajo de 2004 ya planteábamos la potenciación del acceso a la sociedad del conocimiento y la información en plena «Era Digital», caracterizada por la Nueva Economía y Sociedad Red.

3. Inteligencia artificial, robótica, nanotecnología, computación cuántica, biotecnología, Internet de las cosas (IoT), impresión 3D, vehículos autónomos, entre otras. 
de Formación, Información y Comunicación (RedFIC)4, puede jugar un papel relevante de cara a reactivar esos territorios que han venido a denominarse «España Vacías.

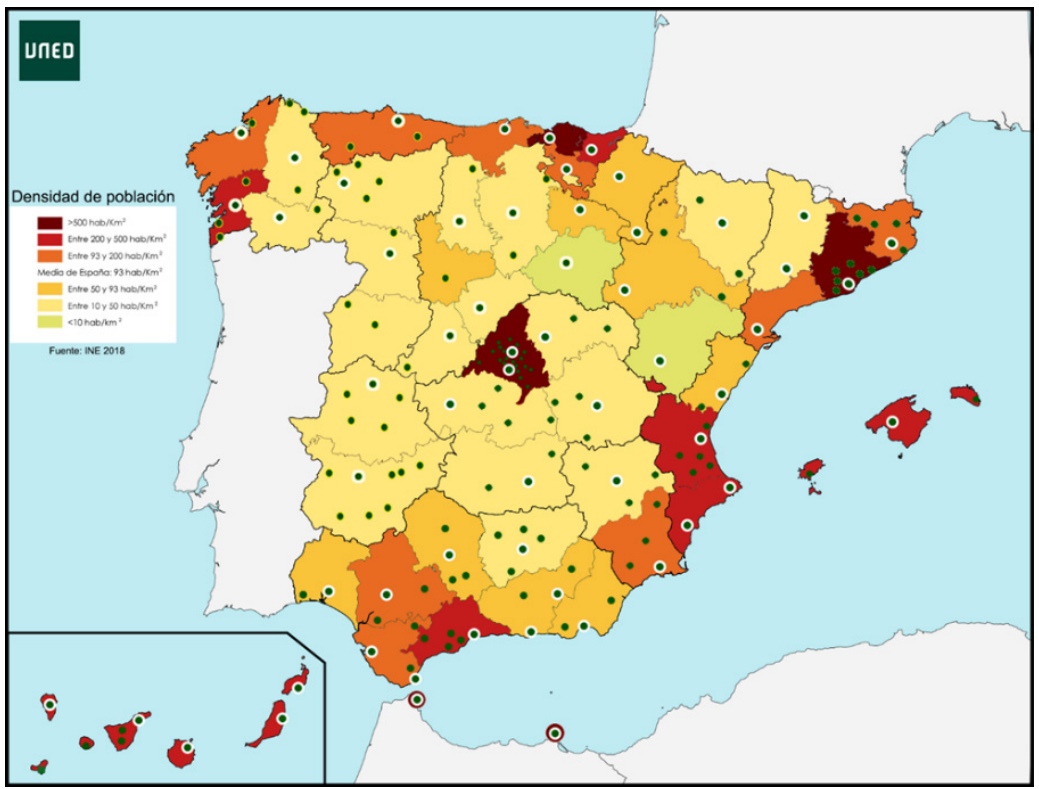

Figura n. ${ }^{\circ}$ 1. El papel de la UNED ante la «España Vacía».

Nuestra propuesta es que los recursos económicos principales -talento, innovación y creatividad- que antes de la pandemia del Covid-19 se concentraban en grandes áreas metropolitanas con una alta densidad de población, pueden descentralizarse y ser más productivos, convirtiéndose en los motores principales del crecimiento económico de territorios como El Bierzo ${ }^{6}$.

4. Vega Núñez, J. (2012). Plataforma AVIP. Una Red Nacional de servicios de Formación, Información y Comunicación.

5. La "España vacía» alude a un proceso de despoblación motivado por causas intrínsecas como puede ser la defunción de los habitantes de un municipio para los que no hay regeneración. Por el contrario, la "España vaciada" apunta a causas extrínsecas, tales como la falta de políticas público-privadas que implican la emigración de su población a la par que no atraen nuevos habitantes. Dado que el presente artículo está centrado en la reactivación de territorios desequilibrados económicamente y en vías de despoblamiento y que no vamos a profundizar en el tipo de causas intrínsecas o extrínsecas que lo han motivado, utilizaremos indistintamente ambas acepciones, que además ya se han "popularizado".

6. Debate entre un mundo plano o puntiagudo con autores como Richard Florida, Thomas L. Friedman o Manuel Castells, entre otros. 
JORGE VEGA NÚÑEZ Y JOSÉ LUIS CALVO GONZÁLEZ

EL OBSERVATORIO DEL NOROESTE IBÉRICO: EMPRENDIMIENTO SOCIAL PARA UN TERRITORIO SOSTENIBLE

El Bierzo, como territorio que pretende adaptarse al modelo económico propuesto, necesita contar con entidades y empresas que aprendan a trabajar en red, sean innovadoras y capaces de atraer y retener talento, en un enfoque alineado con la visión europea, desde la estrategia de Lisboa de 2000 a la estrategia europea de datos de $2020^{7}$.

\section{Un Modelo de Desarrollo local Basado en una Red De EMPRENDimiento SOCIAL}

¿Qué Modelo proponemos desde la UNED para que El Bierzo pueda aprovechar dicha oportunidad?

A lo largo del presente trabajo veremos cómo teniendo en cuenta las dos condiciones definitorias puede resultar factible alcanzar el objetivo general de lograr un desarrollo territorial sostenible que logre fijar población reactivando territorios desequilibrados económicamente y en vías de despoblamiento.

\section{A) Objetivo: Desarrollo territorial}

El desarrollo territorial puede plantearse como un proceso coherente y sostenible de desarrollo económico y social en un determinado territorio que posee unas características particulares, políticas, económicas, sociales y medio ambientales, que le diferencian de los demás ${ }^{8}$. Dicho proceso necesita de la colaboración y cooperación de todos los actores sociales, públicos y privados, existentes en dicho territorio, para poder alcanzar el éxito. Presupone así, que tales sujetos son capaces de coordinarse, de aunar esfuerzos y de participar en redes sociales que les permitan alcanzar el objetivo común.

\section{B) Redes Sociales y Desarrollo Territorial}

El desarrollo territorial depende en buena medida de la gobernanza del territorio y ésta se encuentra estrechamente vinculada con las Redes Sociales que se establezcan en el mismo?.

7. https://ec.europa.eu/info/strategy/priorities-2019-2024/europe-fit-digital-age/ european-data-strategy_es

8. Bien diseñado, puede resultar un mecanismo eficaz para la erradicación de la pobreza, de la exclusión social, de las desigualdades en la distribución de la renta, del deterioro medioambiental, de la despoblación que sufren determinadas zonas geográficas, etc. Además, puede servir como mecanismo para la conservación y mantenimiento de no sólo del medio ambiente, sino también, del patrimonio histórico y cultural; preservando así la identidad y tradición de las diferentes comunidades.

9. Vega Núñez, J. (2014) Capítulo VII. ARS Tecnología, Economía y Desarrollo Territorial. Libro "Conectados Por Redes Sociales: Introducción al análisis de redes sociales y casos prácticos", coordinado por Miguel del Fresno, Pilar Marqués y David S. Paunero 
En este sentido, a la hora de diseñar una red social que contribuya al desarrollo local, deben tenerse en cuenta una serie de aspectos:

En primer lugar, que los procesos de cambio en la gobernanza y en los sistemas de innovación están generando dinámicas territoriales cada vez más complejas de analizar, debido a las interconexiones a través de continentes, países y regiones. Estos cambios demandan modelos de análisis que capturen dicha complejidad, en concreto herramientas para difundir los beneficios de los procesos y mitigar las desventajas competitivas ${ }^{10}$. En este contexto, existe un consenso en aumentar la interconectividad entre las economías regionales para conseguir un desarrollo nacional, a través de un aprendizaje mutuo y políticas de transferencia. Evidencias empíricas han demostrado cómo la eficiencia de los sistemas de innovación regional, la génesis de estructuras políticas y locales y la proximidad de redes, puede influir en la difusión geográfica del conocimiento ${ }^{11}$. La estructura relacional de un grupo de emprendedores, de su grupo de socios, de amigos, de su familia, etc., puede ser analizada desde lo que el Análisis de Redes Sociales denomina variables estructurales, o lo que es lo mismo, variables que analizan de forma conjunta los actores y sus contactos ${ }^{12}$.

En segundo lugar, el diseño de la red debe tener en cuenta a los actores influyentes, qué tipo de conexiones favorecen la innovación, qué estructuras o redes consolidan un proyecto empresarial, quién y con quién facilitan la fidelización de un producto, etc. En este sentido, los modelos de redes sociales utilizan la estructura como un indicador sobre cómo la información es distribuida en un sistema de personas. Dichos modelos se construyen conforme a dos premisas: las personas forman clusters dentro de los grupos como resultado de las interacciones definidas por los lugares donde la gente contacta, y la segunda, la comunicación puede ser muy frecuente e influente dentro de esos clusters ${ }^{13}$. A partir de aquí se deben considerar, por una parte, un nivel de conexiones directas y cercano $^{14}$, y por otra, conexiones indirectas cruzando las barreras locales y regionales para

10. Crescenzi and Rodríguez-Pose, 2012.

11. Crescenzi and Rodríguez-Pose, 2012. En este sentido y dado que las ciencias sociales, especialmente la economía y la sociología no parecen llegar a un acuerdo sobre si la perspectiva micro precede a la macro o viceversa, se considera necesario un marco nuevo de estudio capaz de buscar puentes integradores entre ambos (Bögenhold, 2013) y capaz de analizar todas las interconexiones que pudieran establecerse entre dichos niveles.

12. El concepto de red "acentúa el hecho de que cada individuo tiene lazos con otros individuos, y cada uno de ellos está a su vez ligado a unos pocos, a algunos o a muchos otros, y así sucesivamente» (Wasserman y Faust, 2013).

13. A partir de aquí, las personas crean sistemas de expresión, de opinión, símbolos y comportamientos definidos por ser miembros de esa estructura o red (Burt R., Kilduff M., and Tasselli S, 2013).

14. Teniendo en cuenta, por ejemplo, cómo un proyecto empresarial puede arraigarse en el territorio, qué actores favorecen este anclaje, cómo se produce el contagio de consumo hacia un producto y cómo se teje una red colaborativa basada en la confianza y la competencia para generar y desarrollar valor económico. 
conceptualizar un modelo de desarrollo territorial que no coincide con los límites geográficos ${ }^{15}$. Por supuesto, en este punto se trata de identificar a los líderes influyentes a nivel local, los líderes intermediarios que hagan de puentes entre los territorios, etc.

En tercer lugar, el análisis de la red social se debe llevar a cabo de una forma dinámica y solapada. Dinámica porque las redes sufren transformaciones por la influencia constante del entorno y solapada porque en esa visualización deberíamos superponer las redes con contactos más frecuentes y las redes con contactos más lejanos ${ }^{16}$. Este enfoque es importante para un proyecto de desarrollo que pretenda analizar las estructuras a nivel local y sus lazos indirectos extendidos a nivel regional, nacional o incluso internacional. Es decir, se trata de considerar una perspectiva polimórfica y multidimensional donde el desarrollo territorial se contemplaría no sólo en base territorial sino en torno a una geografía relacional ${ }^{17}$.

15. Es decir, cómo se genera el sentido de pertenencia a un proyecto, cómo se establecen lazos fuertes basados en una reciprocidad colaborativa, etc, pero con una baja frecuencia de contactos e incluso distanciada geográficamente. El estudio de la innovación a través de contactos no redundantes fue llevado a cabo por Burt (2000) con tu Teoría de los Structural Holes, basada en que para innovar es necesario tener contactos no redundantes, es decir, distanciados en el tiempo e incluso en la geografía. La innovación y la generación es difícil que surja en el ambiente laboral más cotidiano, puesto que todos los trabajadores tendrían más o menos la misma información. En este sentido Granovetter (1973) con su estudio de la fuerza de los lazos débiles, también subraya las oportunidades que se generan mediante este tipo de redes.

16. El soporte para esta propuesta lo encontramos en los estudios de Vanhaverbeke et al (2012) en "competence and governance in strategic collaboration: the differencial effect of network structure on the creation of core and noncore technology". Los investigadores recogen los estudios de Granovetter (1992), de Burt (1992b) y de Coleman (1988) para hacer una propuesta sobre la complementariedad de los lazos directos e indirectos, haciendo un llamamiento de la necesidad de ambos tipos de contactos y por tanto de redes. Granovetter (1992), atendiendo a los lazos directos e indirectos, hacía una distinción que denominó embeddedness relacional y embeddedness estructural. La primera hace referencia a las relaciones de los socios con quienes las empresas tienen contactos directos. En este caso la información es más redundante y favorece que fluya el conocimiento. Para Coleman (1988) son las redes idóneas para disminuir el riesgo de la gobernanza y construir relaciones basadas en la confianza. La segunda se refiere a la información que fluye desde los socios de los socios e incluso a más pasos, es decir, relaciones indirectas. En este caso Burt (1992b) subraya que este tipo de relaciones favorece el acceso a nuevas oportunidades. Para resumir, Vanhaverbeke et al (2012) proponen una complementariedad entre el embeddedness relacional y embeddedness estructural, o lo que es lo mismo, los lazos directos e indirectos.

17. Andreas F. (2013) describe, metafóricamente hablando, que los territorios están formados por pequeñas islas con relaciones armónicas en el archipiélago, de forma que un territorio no es un "Contenedor" cerrado, lleno de contenidos y estrategias políticas inamovibles, sino que responde a un proceso dinámico, regulado por la gobernanza y en continua transformación. 


\section{C) Redes Sociales Digitales y Desarrollo Territorial}

Podemos definir una red social digital ${ }^{18}$ como un sitio en internet cuya finalidad es permitir a los usuarios relacionarse, comunicarse, compartir contenido y crear comunidades, siendo también una herramienta de democratización de la información que transforma a las personas en receptores y en productores de contenidos.

De esta manera, Internet ha propiciado la hiperconexión, dando lugar a nuevas formas que introducen cuatro modificaciones en los tipos de interacciones sociales analógicas/reales: Enormidad: Se incrementa el número de conexiones y personas a los que podemos llegar. Comunalidad: Se amplía la escala en la que podemos compartir información y trabajo colaborativo en red. Especificidad: Se incrementa la capacidad de crear vínculos sobre temas más particulares. Virtualidad: Aparece la capacidad de asumir identidades virtuales.

En este sentido, una red social digital para el desarrollo local, constituida por emprendedores, productores locales y las relaciones que se establecen con la comunidad de usuarios $^{19}$ puede asentarse en el concepto de compra social ${ }^{20}$. Dicha red habrá de tener capacidad para propagar la creatividad y el trabajo colaborativo en red, y en su diseño habrá de considerarse la especial relación entre identidad y confianza mutua ${ }^{21}$. Se tratará de una red de tamaño grande según su número de nodos $^{22}$ y con un esperado alto grado de actividad entre ellos. Se requerirá, por

18. El software social que da soporte a las redes sociales digitales parte de la teoría de los seis grados de separación, según la cual toda la gente del planeta está conectada a través de no más de seis personas.

19. Bussiness Network (Ritter, 2013).

20. Será una red social en la que tanto productores como consumidores podrán comunicarse entre ellos. No pretende promover una marca de calidad tradicional, sino que, mediante la red, los consumidores crean una marca de confianza interactuando entre ellos. Irán siguiendo unas pautas marcadas por unos influenciers.

21. La identidad genera una tensión entre los que pertenecen y los que no pertenecen a una red. Esta tensión refleja una contradicción entre la que se mueve todo ser humano, la individualidad y la llamada de la especie. En relación al conflicto entre identidad y confianza mutua, una característica de las redes sociales digitales es la tendencia a pertenecer a todas las redes posibles. Dicha multipertenencia pone en juego la generación y el sostenimiento de la confianza mutua. En las redes sociales analógicas, que tenían pocos solapes, la identidad era una cuestión de pertenencia y la confianza mutua era una consecuencia inmediata. Sin embargo, en las redes digitales la identidad es una cuestión de multipertenencia, las redes son muy solapadas pero la confianza mutua no es automática. De hecho, un reto para la empresa en la economía del conocimiento es lograr que su presencia en las redes digitales se acompañe de una fuente independiente de confianza.

22. El indicador que define una de las propiedades principales de las redes es el número de nodos que aparecen en ésta. Así, en el trabajo Katy Börner y sus coautores se propone una clasificación de las redes en función de su número de nodos (Börner et al., 2007), denominando redes pequeñas a aquellas que están formadas hasta por cien nodos, de tamaño medio a aquellas que están formadas por entre cien y mil nodos y finalmente redes grandes cuando se forman por más de mil nodos. 
JORGE VEGA NÚÑEZ Y JOSÉ LUIS CALVO GONZÁLEZ

EL OBSERVATORIO DEL NOROESTE IBÉRICO: EMPRENDIMIENTO SOCIAL PARA UN TERRITORIO SOSTENIBLE

tanto, un soporte tecnológico adecuado para realizar el Análisis de Redes Sociales de gran tamaño ${ }^{23}$.

En definitiva, cuando tratamos de desarrollo local y redes digitales debemos acabar considerando que los territorios desconectados tienen que afrontar las desigualdades territoriales y sus consecuencias sociales y económicas. Estos territorios deben hacer frente a la Brecha Digital que provoca una situación de deterioro económico y social permanente.

\section{D) Economía Social y Desarrollo Territorial.}

Otro aspecto fundamental de la red social diseñada para contribuir al desarrollo local es que se basa en la economía social, entendida como conjunto de actividades económicas y empresariales, que en el ámbito privado llevan a cabo aquellas entidades que, persiguen bien el interés colectivo de sus integrantes, bien el interés general económico o social ${ }^{24}$. De esta forma, los emprendedores sociales que participen en la red digital constituida para promover el desarrollo local habrán de respetar unos principios básicos de actuación:

a) Primacía de las personas y del fin social sobre el capital, que se concreta en gestión autónoma y transparente, democrática y participativa, que lleva a priorizar la toma de decisiones más en función de las personas y sus aportaciones de trabajo y servicios prestados a la entidad o en función del fin social, que en relación a sus aportaciones al capital social.

b) Aplicación de los resultados obtenidos de la actividad económica principalmente en función del trabajo aportado y servicio o actividad realizada por las socias y socios o por sus miembros y, en su caso, al fin social objeto de la entidad.

c) Promoción de la solidaridad interna y con la sociedad que favorezca el compromiso con el desarrollo local, la igualdad de oportunidades entre hombres y mujeres, la cohesión social, la inserción de personas en riesgo de exclusión social, la generación de empleo estable y de calidad, la conciliación de la vida personal, familiar y laboral y la sostenibilidad.

d) Independencia respecto a los poderes públicos.

23. Sin pretender hacer un inventario exhaustivo de la oferta actual de herramientas que tienen como finalidad el tratamiento y visualización de redes Big Data, se enumeran los principales: GEPHI, Citoscape, Giny, graphviz, HyperGraph, Hypertree, InfoVisToolkit, IsaViz, JGraph, JUNG, LGL, LibSea, Mondrian, OpenDX, Otter, Pajek, Piccolo, Prefuse, RDF Gravity, SemaSpace, TouchGraph, Tulip, Visual Browser, Walrus, xSiteable, etc. Social.

24. Como establece, por ejemplo, el artículo 4 de Ley 5/2011, de 29 de marzo, de Economía 


\section{E) Empresa Red y Desarrollo Territorial}

Un aspecto clave que habrán de tener en cuenta dichos emprendedores sociales es la necesaria adaptación a la economía del conocimiento, utilizando la información y los nuevos canales como un elemento decisivo de apoyo a sus actividades económicas, es decir, la conveniencia de funcionar como una «Empresa Red ${ }^{25}$. El objetivo de este enfoque es que la comunicación fluya horizontalmente permitiendo un mayor intercambio de información y el fomento de la creatividad, concentrándose asimismo en las actividades en las que se posea una verdadera ventaja competitiva.

En este punto, consideramos que la industria creativa ${ }^{26}$, entendida como fusión entre la industria cultural y la economía del conocimiento, supone un sector de actividad clave para la reactivación de los territorios con desequilibrios socioeconómicos y en vías de despoblamiento. De esta forma, el emprendedor social habrá de fomentar la creatividad aprovechando los nuevos usos y aplicaciones de la información que están suponiendo una auténtica transformación en la forma de hacer negocios. En efecto, las tecnologías que permiten las nuevas formas de explotar la información no son sólo más baratas y fácilmente adoptables, sino que presentan una serie de ventajas para los agentes productivos ${ }^{27}$.

Como se aprecia en el Gráfico siguiente, la mayor interdependencia entre las actividades productivas que propicia la mejora de la intercomunicación permitirá a los emprendedores flexibilizar de forma significativa sus estructuras productivas mediante la subcontratación de todos los aspectos ajenos a sus capacidades básicas (Core Business).

25. Vega Núñez, J. y Calvo González, J. L. (2016). «Microeconomía. Teoría y Realidad»

26. De esta forma, siguiendo el trabajo de 2001 de John Howkins, la industria creativa es el sector de la economía que involucra la generación de ideas y conocimiento y abarca esencialmente la industria cultural (arte, entretenimiento, diseño, arquitectura, publicidad, gastronomía) y la economía del conocimiento (educación, investigación y desarrollo, alta tecnología, informática, telecomunicaciones, robótica, nanotecnología, industria aeroespacial).

27. Las TICs permiten incrementar la eficiencia en prácticamente toda la cadena de valor de la industria, desde el diseño hasta el marketing, pasando por la gestión de los aprovisionamientos y la contabilidad.

Surgen nuevas oportunidades para que las empresas tradicionales subcontraten todas aquellas actividades ajenas a su actividad nuclear, conectándose con sus proveedores electrónicamente y a bajo coste a lo largo de la cadena de suministros, lo que aumenta su velocidad de acción. La naturaleza horizontal de las TIC hace que se conviertan en la primera revolución tecnológica que aumente la productividad no sólo del sector industrial, sino igualmente de los servicios, por ejemplo, del turismo. Al potenciar el acceso igualitario a la información, las nuevas tecnologías ayudan a que los mercados funcionen más eficientemente, mejorando su transparencia y haciendo que la economía se acerque al modelo de competencia perfecta. Por último, el empleo masivo de las TIC facilita que una cantidad creciente de información pueda ser almacenada y enviada a cualquier lugar del mundo, de forma instantánea y a un precio mínimo. De esta forma, las nuevas tecnologías aumentan el ritmo de globalización de los mercados generando un círculo virtuoso de causas y efectos que se realimentan. 


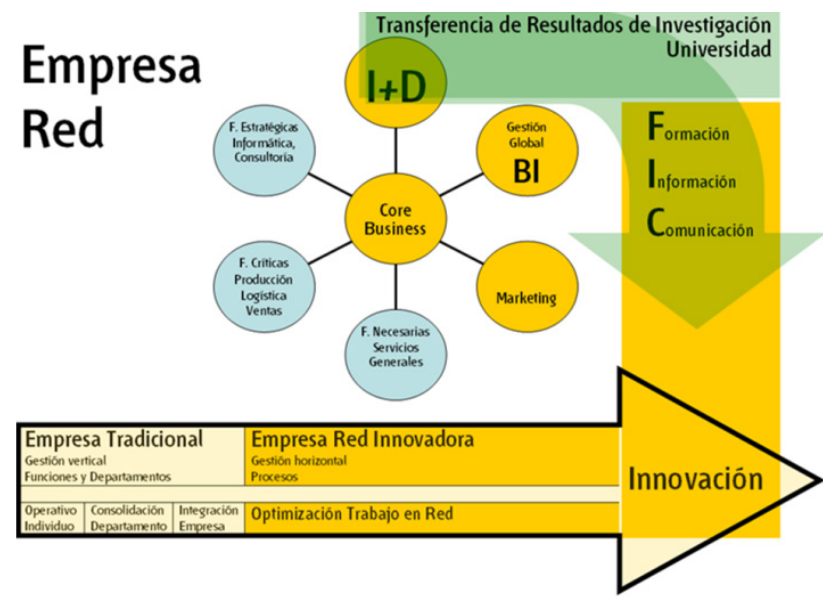

Figura n. ${ }^{\circ}$ 2. Empresa Red y desarrollo territorial.

De esta forma, desaparece la necesidad del recurso a las integraciones verticales como medio de afrontar los costes fijos y asegurar las economías de escala en la producción, mientras que, por el contrario, las economías de alcance logradas mediante acuerdos estratégicos con terceros, gracias al soporte de las nuevas tecnologías, se convierten en un aspecto determinante para asegurar la eficiencia operativa. Todo esto tiene consecuencias muy importantes sobre el tamaño óptimo de las empresas, que se ve reducido. De esta forma, en este modelo el tamaño deja de ser una garantía de éxito y permanencia en el mercado ${ }^{28}$. La importante consolidación del comercio B2B basada en las tecnologías es una clara oportunidad para los emprendedores sociales que podrán beneficiarse del aumento de la eficiencia ${ }^{29}$. En conclusión, logran la profundización de la competitividad

28. Las TIC están propiciando en las empresas algo más que la eclosión del comercio electrónico característico del comercio al consumidor (B2C): la potenciación del funcionamiento de la Empresa Red que se sustenta más en el comercio entre empresas (B2B), conectando a las compañías y a sus proveedores electrónicamente a lo largo de toda la cadena de suministros.

29. Reduciendo los costes de los aprovisionamientos, en la medida que hace más fácil para los emprendedores encontrar proveedores más baratos y eficientes. Realizando órdenes de compra on line, que permiten superar muchos de los errores derivados de los sistemas de pedidos tradicionales. Posibilitando ahorros derivados de menores costes de transporte y distribución en bienes y servicios que pueden ser entregados electrónicamente, eliminando así las barreras de la distancia, como los servicios financieros y el software. Creando una mayor conexión entre los ciclos de la cadena de producción (aprovisionamiento, transformación, almacenaje y distribución), que se traduce en un menor tiempo de vulnerabilidad desde que el emprendedor emite un pedido hasta que lo recibe y en una mayor velocidad (economía de velocidad) de respuesta para el cliente. Aumentando la eficiencia, la posibilidad de elección y la velocidad (economía de velocidad) en la gestión de la cadena de suministros, eliminando en muchos casos la figura de los intermediarios y minimizando los estrangulamientos 
potenciando la capacidad de competir en igualdad de condiciones para todos los emprendedores.

El emprendedor social deberá aprovechar las características antes aludidas de las redes sociales digitales para diseñar su estrategia de maximización de beneficio. En concreto, puede explotar la especificidad vía la economía de la larga cola y la comunalidad haciendo uso de la economía de la colaboración y los efectos de red.

En cuanto a la especificidad, incrementa la capacidad de crear vínculos sobre temas particulares y supone una oportunidad para los emprendedores sociales a través de la Economía de la larga cola ${ }^{30}$. En este sentido, Internet y el entorno digital han cambiado las reglas del mercado. La reducción en el coste de almacenamiento y distribución que permiten las nuevas tecnologías hace que no sea ya necesario orientarse hacia unos pocos productos de éxito. Además, las restricciones físicas no son significativas en el entorno digital. Esto posibilita la convivencia de dos mercados: el tradicional centrado en el alto rendimiento de unos pocos productos - la cabeza- y otro basado en la suma de las pequeñas ventas de muchos productos que pueden igualar e incluso superar al primero -la cola-. En definitiva, la hiperconexión propiciada por internet permite la puesta en marcha de nuevos modelos de negocio, ya que cualquier producto por minoritario que sea puede tener acceso a su propio mercado a través de la red ${ }^{31}$.

Para alcanzar estos resultados y tener éxito en este modelo de negocio es preciso seguir tres reglas:

- $\quad$ poner el producto en el mercado, por minoritario que sea ${ }^{32}$.

y la incertidumbre operacional. Anticipando la demanda y las tendencias del mercado, gracias a la disponibilidad de un flujo constante de información desde los puntos de venta hasta los centros de diseño y producción. Permitiendo una profundización en los sistemas de logística integrada, el diseño de la gestión de la cadena de suministro y la producción flexible o, al racionalizar los procesos operativos, promoviendo la colaboración estratégica y las comunidades de negocios.

30. La Ley de Pareto o regla del 80/20 establece que el $20 \%$ de los productos obtiene el $80 \%$ de los ingresos. A esto había que añadir en el modelo tradicional de negocio las limitaciones geográficas y físicas y el coste de almacenaje y distribución de productos. Por todo ello la empresa debía concentrarse en una audiencia numerosa y generar una gran demanda en un ámbito geográfico manejable para que fuera rentable su negocio, focalizando su actividad en unos pocos artículos fácil y rápidamente vendibles.

31. Así, Amazon obtiene entre el 25 y $30 \%$-el 57\% según algunos estudios- de sus ingresos de la venta de libros que no son los habituales superventas; el $20 \%$ de las películas que alquila Netflix son documentales, películas de serie B, para minorías, etc. o el $22 \%$ de la ventas de Rhapsody, descarga de música por suscripción, provienen de canciones que no se escuchan en los medios de comunicación normales.

32. Una vez superadas las barreras del espacio y del tiempo, lo que importa no es donde están los usuarios, ni siquiera si hay muchos, únicamente importa que existan algunos, en cualquier parte. 
JORGE VEGA NÚÑEZ Y JOSÉ LUIS CALVO GONZÁLEZ

EL OBSERVATORIO DEL NOROESTE IBÉRICO: EMPRENDIMIENTO SOCIAL PARA UN TERRITORIO SOSTENIBLE

- fijar un precio acorde a los costes de producción ${ }^{33}$.

- facilitar las búsquedas de nuestro producto por parte del usuario ${ }^{34}$.

En cuanto a la Comunalidad de las Redes digitales, supone la ampliación de la escala en la que podemos compartir información y desarrollar trabajo colaborativo en red, dando origen a la economía de la colaboración ${ }^{35}$. Las dimensiones de este modelo se extienden tanto, a la producción (por ejemplo, crowdsourcing, plataformas de innovación colectiva, open software contenidos generados por usuarios, coworking), la financiación (iniciativas de crowdfunding) como al consumo (compra social)». Este tipo de economía se sustenta en que las redes sociales digitales conforman redes de personas que comparten una identidad y tienen confianza mutua. Esto, por un lado, convierte a los individuos en agentes activos que pueden actuar en colaboración si los compromisos entre ellos son firmes y creíbles y, por otro lado, al conectar directa o indirectamente cada persona con muchas otras surgen muchas oportunidades de intercambio que antes se desconocían o no se podían aprovechar por falta de confianza y que pueden llegar a proporcionar nuevas formas, más baratas, de acceso a los bienes y hasta nuevos bienes.

Es en este contexto colaborativo donde aparecen las externalidades que generan rendimientos crecientes, pero desde el lado de la demanda. Estas externalidades $^{36}$, denominadas también efectos de red $^{37}$, adquieren una importancia crucial

33. Si fijamos los precios de acuerdo a los costes digitales y éstos bajan merced al desarrollo tecnológico, los precios bajarán y los consumidores comprarán más; dada la elasticidad de estos productos, que no suelen ser considerados imprescindibles y que cuentan con buenos sustitutos, los ingresos del productor también aumentarán. En la Larga Cola merced a la distribución online podemos pasar de la escasez a la abundancia dado que con limitados costes de almacenamiento y de fabricación y casi sin costes de distribución un contenido adicional presenta costes marginales tendentes a cero. En una economía en la que la competencia puede ser muy alta gracias a la mayor información disponible por todos los usuarios el precio tiende a igualarse al coste marginal y con ello acercarse a la «economía de lo gratuito".

34. En este modelo se pueden producir grandes cantidades y de todas las calidades. Por esta razón, se hace imprescindible introducir filtros de colaboración social (por ejemplo, el etiquetado social) que dirijan la atención hacia un lado u otro, ignorando aquello que no interesa a los usuarios.

35. Se llama Economía en colaboración a «un nuevo modelo de intercambio económico que se basa en tres principios fundamentales: interacción entre productor y consumidor, que mantienen un diálogo continuo, conexión entre pares, gracias a las tecnologías, especialmente digitales, y la colaboración.

36. En función de los factores que explican los beneficios externos generados por un usuario al conectarse a una red podemos diferenciar tres tipos de externalidades: Directas. Indirectas y de Aprendizaje.

37. El efecto red implica que el valor y la utilización de un determinado soporte o infraestructura tecnológica aumentan cuantos más usuarios haya del mismo, al aumentarse la interactividad. Esta propiedad es el resultado de una retroalimentación positiva en el proceso de asentamiento de las nuevas tecnologías de la información. Además, cuanto mayor sea la demanda mayor será la oferta, con lo que las TIC influyen por ambas vías en el equilibrio del mercado. 
JORGE VEGA NÚÑEZ Y JOSÉ LUIS CALVO GONZÁLEZ

EL OBSERVATORIO DEL NOROESTE IBÉRICO: EMPRENDIMIENTO SOCIAL PARA UN TERRITORIO SOSTENIBLE

en presencia del desarrollo de las TIC. Las redes sociales digitales pueden reforzar estos efectos de red incrementando la productividad del sistema económico, no por la reducción de los costes de transacción sino por el incremento de output que se producirá cuando la proliferación de redes nos lleve en el límite a una situación de competencia perfecta.

Los efectos de red tienen una gran importancia en la Economía del Conocimiento, ya que hacen que «el valor de un producto o servicio dependa no sólo del producto en sí mismo sino del número de usuarios que utilicen dicho producto o servicio ${ }^{38}$. Como resultado, el crecimiento es un imperativo estratégico no solamente para economías de escala en la producción, sino también para conseguir las economías de escala del lado de la demanda generadas por los efectos de red. La clave para la aparición de efectos de red es la existencia de cierta complementariedad y/o interacción entre la tecnología de los distintos usuarios individuales, lo que produce dos efectos fundamentales en la dinámica de la Industria: Se modifica el atractivo de la red, generando economías de escala del lado de la demanda ${ }^{39}$, y los potenciales consumidores consideran en su decisión de compra las expectativas futuras de éxito de las distintas redes en competencia.

Sin embargo, incluso existiendo efectos de red, la heterogeneidad en las preferencias de los consumidores, así como la diferenciación de productos pueden hacer que varias redes coexistan de forma simultánea, ya que determinados usuarios pueden preferir la ventajas intrínsecas de un producto aunque esto implique pertenecer a una red de menor tamaño. En definitiva, los emprendedores sociales pueden tener su oportunidad en este escenario, siempre que logren diferenciarse y "convencer" a los consumidores de las «ventajas sociales y medioambientales» de sus productos y servicios.

\section{Aplicación del Modelo: Resultados y Proyectos en marcha}

¿Qué resultados en proyectos concretos estamos obteniendo desde la UNED a la hora de ayudar a la reactivación territorial de forma efectiva?

Para comenzar, y como ejemplo práctico de planteamiento colaborativo en relación con la gobernanza territorial, en 2011 se firma un convenio entre UNED, ULE y CIUDEN para la puesta en marcha del Observatorio Territorial del

38. Las tecnologías de las comunicaciones son un caso paradigmático (los teléfonos, el correo electrónico, el acceso a Internet, etc.), pero estos efectos de red no se ciñen solamente a las redes de comunicaciones, son también muy importantes en las redes sociales digitales (por ejemplo, la red de usuarios de Apple). Debido a que estas redes sociales de usuarios compatibles generan efectos de red, los sistemas populares de hardware y software disfrutan de una ventaja competitiva importante sobre los sistemas menos populares.

39. Esto implica que el precio que los usuarios pagan está en parte determinado por el tamaño de la red a la que pertenece el producto. 
Noroestes $^{40}$. El Observatorio ${ }^{41}$ se define como una institución centrada en promover el desarrollo sostenible (alineado con la agenda 2030 y los objetivos de la UE), para crear, consultar, utilizar y compartir la información y el conocimiento, de forma que los distintos agentes sociales, económicos, ambientales y políticos puedan emplear plenamente sus posibilidades en su promoción.

El objetivo es promover un modelo de gobernanza territorial basado en la gestión integrada del conocimiento ${ }^{42}$, que contribuya a la toma de decisiones en materia de políticas, programas y acciones de desarrollo sostenible por parte de los actores locales relevantes y pueda así alcanzar un importante ascendiente social $^{43}$. De esta forma, el Observatorio aspira a ser un lugar de encuentro para el intercambio de información y experiencias, propiciando un espacio para la reflexión y el diálogo abierto, entre cualquier parte interesada en el desarrollo sostenible, como las administraciones, las instituciones de investigación, los agentes económicos, sociales y medioambientales, y la sociedad civil, siempre con un enfoque participativo y creativo.

En este sentido, el Observatorio trata de desarrollar un Modelo de gestión integrada del conocimiento.

- Que contribuya a la toma de decisiones en materia de políticas, programas y acciones de desarrollo sostenible.

40. http://observatorionoroeste.es/

41. Los Objetivos del Observatorio son: Potenciar la generación de información y conocimiento en materia de desarrollo territorial, contribuyendo a la mejor información y participación en las estrategias locales para un Desarrollo Sostenible; establecer las vías adecuadas que permitan tratar coherentemente asuntos transversales como las redes sociales, la eficiencia energética, el emprendimiento, la internacionalización o las TICs; fomentar la integración vertical y la coherencia entre los niveles nacional, autonómico y local en la definición de políticas y en su puesta en práctica; desempeñar un papel activo, actuando como catalizadores del debate en materia de desarrollo territorial; Generalizar los conceptos y los diversos aspectos que conforman el desarrollo territorial, organizando actos en colaboración con los agentes económicos, sociales e institucionales, así como con la sociedad civil para difundir nuevas ideas, intercambiar las mejores prácticas y aumentar la conciencia pública en el ámbito del desarrollo territorial sostenible. Las Actividades se han centrado en Cuatro tipos de tareas básicas: Investigación en las áreas de trabajo (Grupos de Innovación e investigación en materia sociosanitaria, energías renovables, sector agroalimentario, internacionalización, comunicación y marketing, TICs, etc.); Asistencias técnicas; Difusión del conocimiento (Cursos, Talleres técnicos y profesionales, Sesiones orientadas al público) y Soporte institucional (Apoyo a instituciones públicas y privadas, Cooperación y redes, Cooperación con los Grupos de Investigación de las Universidades (SALBIS, MIO, ATLAS, GIPH, etc.)).

42. El conocimiento, la información y la participación son esenciales para el progreso, la buena gobernanza, la acción y diversidad social y el bienestar de los seres humanos en el marco de la sostenibilidad.

43. En este sentido, se trata de aprender y evitar los errores del pasado, como el uso inapropiado de los fondos MINER o la falta de inversiones estructurales en la región (falta de cobertura y digitalización del entorno rural, problemas sanitarios por falta de personal y servicios, inconvenientes en la red de comunicaciones, etc.) que han supuesto un obstáculo para el desarrollo de la región. 
JORGE VEGA NÚÑEZ Y JOSÉ LUIS CALVO GONZÁLEZ

- Que aspira a ser un lugar de encuentro para el intercambio de información y experiencias.

- Que trata de propiciar un espacio para la reflexión y el diálogo abierto, entre cualquier parte interesada en el desarrollo territorial sostenible.

- Que parte de un enfoque multidisciplinar y participativo que trata de fomentar la industria creativa.

De esta forma, desde 2011 el Observatorio ha tratado de constituirse en lugar de referencia para la gestión del conocimiento territorial y la sostenibilidad para todo el cuadrante noroccidental peninsular. En este sentido, El Bierzo, como territorio-punto de partida, puede ser considerado como un gran laboratorio territorial dado que muestra muchos de los problemas nacionales en cuanto a la gestión del territorio, los recursos naturales, el modelo económico, etc.

Los Principios de actuación del Modelo de Gobernanza Territorial del Observatorio son la Diplomacia institucional, científica y cultural, la Colaboración, la Corresponsabilidad y la Transparencia. El Observatorio adoptó una «estrategia bottom-up" que, soportada en varios grupos de investigación de las dos universidades que lo promueven, le permitiría mantener en el tiempo su actividad de adquisición del conocimiento y curriculum indispensables para seguir avanzando en el objetivo perseguido. De esta forma, entre 2011 y 2019 el observatorio desarrolló una intensa actividad de investigación en diferentes líneas de trabajo ${ }^{44}$, asistencias técnicas, difusión del conocimiento ${ }^{45}$, soporte institucional ${ }^{46}$ y cooperación y redes. Estas actividades se han organizado a través de cuatro áreas: sectores económicos, políticas locales, territorio y sociedad ${ }^{47}$. Entre estas actividades destacan la celebración de tres Congresos sobre análisis de redes sociales y desarrollo territorial (en 2011, 2013 y 2015) y dos Congresos Territoriales del Noroeste Ibérico (en 2012 y 2015).

Desde el observatorio se impulsaron también tres proyectos que en 2019 acabarían siendo aglutinados en una Cátedra Universidad Empresa sobre "Turismo Sostenible y Desarrollo Local»: la Red de Economía Social y Desarrollo Territorial, el Grupo de trabajo sobre Patrimonio Minero del Noroeste Ibérico y el proyecto de Tecnologías de la Información Aplicadas al Desarrollo Territorial.

44. Desarrollada por grupos de Innovación e investigación de la UNED y la ULE especializados en materia socio-sanitaria, energías renovables, sector agroalimentario, internacionalización, comunicación y marketing, TICs, etc. (SALBIS, MIO, ATLAS, GIPH, etc.).

45. A través de Cursos, talleres técnicos y profesionales, sesiones orientadas al público, etc.

46. Apoyo tanto a instituciones públicas como privadas.

47. En este tiempo se ha producido una mayor especialización en aspectos que consideramos claves para la reactivación del territorio: energías renovables, sector agroalimentario, aspectos sociosanitarios, tecnologías de la información, emprendimiento, comunicación y marketing, internacionalización, economía del bienestar, participación ciudadana y modernización de las políticas públicas, puesta en valor del patrimonio, turismo sostenible e inteligente, etc. 


\section{A) Emprendimiento Social y Desarrollo Local}

El primero de estos proyectos es la «Red de Emprendimiento y Desarrollo Local (RESDT)» ${ }^{48}$, que comenzó como proyecto de investigación ${ }^{49}$ y derivó en la puesta en marcha de una Red Social, sin ánimo de lucro y de suscripción voluntaria, en la que se realizarían dos tipos de actividades: por un lado, la exposición y comercialización de productos y servicios procedentes de la economía social y, por otro, la realización de eventos culturales, divulgativos y formativos relacionados con la economía social y el desarrollo territorial.

Se trataba, por tanto, de promover el desarrollo territorial a través del impulso de la economía social y solidaria ${ }^{50}$, con un esquema de funcionamiento que se resume en el siguiente gráfico.

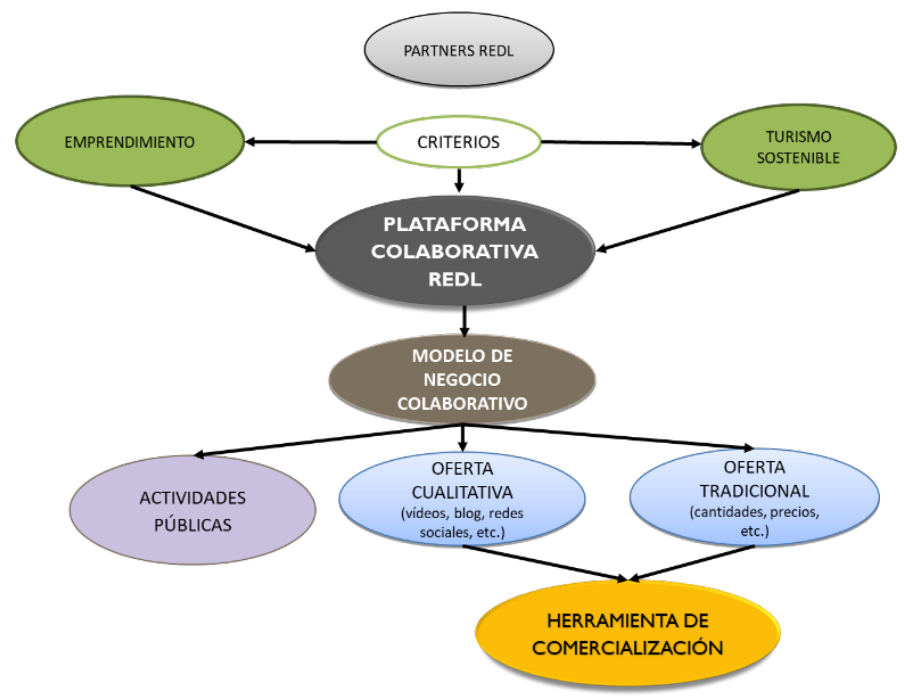

Figura n. ${ }^{\circ}$ 3. Esquema de la Red de Emprendimiento y Desarrollo Local.

48. http://resdt.es/

49. La investigación incluía una revisión de la literatura de la teoría de la demanda basada en el comportamiento racional del consumidor, además de los factores que influyen en las decisiones de compra de los consumidores relacionados con la teoría del Behavioral economics y con los trabajos de Akerlof. Se consideraban el enfoque de las características de Lancaster y la economía de la larga cola. Se concluía definiendo la teoría de la demanda aplicada a la RESDT como un modelo ANCOVA con cantidad, precio, valoración y renta como variables cuantitativas y transparencia, altruismo y red social como cualitativas.

50. El proyecto trataba de promover actividades económicas estrechamente relacionadas con la economía social y favoreciendo la producción y comercialización de productos y/o servicios de alta calidad, se producirá una mejora, no sólo de los territorios e individuos participantes en la Red, sino también de sus entornos (en aspectos sociales, ambientales y económicos). 
Debe tenerse en cuenta que los fundamentos microeconómicos de esta Red de Emprendimiento y Desarrollo Local descansan esencialmente en la "Economía de la experiencia», que además de la funcionalidad de los productos, debe considerar los elementos emocionales y sociales del mismo (lo que el producto dice de nosotros y a quién nos une y separa). Se trata de un elemento emergente del cambio global que pone de relieve la transcendencia de las redes sociales desde un punto de vista económico.

El proyecto de investigación incluía un análisis de la teoría de la demanda aplicada a la Red, que comenzaba introduciendo algo más de realismo sin abandonar la Teoría Económica a través del «el enfoque de las características y la diferenciación de producto de Kelvin Lancaster ${ }^{51}$ : También consideramos la influencia que el comportamiento de otros participantes en la red social tiene sobre nuestra demanda ${ }^{52}$ y las "Preferencias Sociales" ${ }^{53}$. Con todos estos elementos derivamos en el concepto de Compra Social-Compra Colectiva-Club de compras para completar un modelo de negocio basado en el concepto de mercado social y la inclusión de aspectos relevantes de la parte de la oferta como la "Economía de la Larga Cola»y la "Economía Colaborativa».

Por otra parte, en el diseño del proyecto tuvimos en cuenta que el desarrollo territorial depende, en buena medida, de la gobernanza del territorio y ésta se encuentra estrechamente vinculada con las Redes Sociales que se establezcan en el mismo. De esta forma, los territorios desconectados tienen que afrontar desigualdades territoriales ${ }^{54}$ y sus consecuencias sociales y económicas en educación, sanidad, renta, etc.

Para responder de forma efectiva a todas las cuestiones aquí planteadas, la Red Social utilizaría como soporte tecnológico la Red Nacional de Servicios de Formación, Información y Comunicación de la UNED (RedFIC) ${ }^{55}$.

51. Los consumidores demandan un conjunto de características, no tanto los bienes como tales. Entre estas características o atributos podríamos destacar "producido con valores de economía socialproducto de calidad" "producto que promueve el desarrollo territorial", conceptos que asociamos a "Marca de confianza", en el sentido de conjunto de productos que cumplen con dichas características y/o atributos y que permiten diferenciarlos de otros.

52. Efectos Bandwagon, Snob, Veblen, etc

53. Altruismo, Equidad, Identidad, Estatus.

54. Estos territorios deben hacer frente a la Brecha Digital que se ve agravada por el fenómeno consistente en que los conectados tienden a conectar con otros conectados, mientras los desconectados tienen dificultades crecientes para conectarse y se ven condenados a permanecer en una situación de deterioro económico, social y, en definitiva, territorial.

55. A través de la transferencia de conocimiento en el ámbito del Desarrollo Territorial, facilita la conexión de los territorios más desfavorecidos por la brecha digital, lo que supone unos beneficios evidentes: Igualdad de oportunidades, Bienes y servicios accesibles, Trabajo colaborativo en red e interoperabilidad, Reducción de distancias y costes de desplazamiento, Colaboración institucional e imagen de la Universidad. 
El diseño de la red se basaba en los principios y valores de la economía social y contaba con un elaborado cuestionario para la selección de los emprendedores sociales participantes. En este sentido, uno de los principales problemas a los que se enfrenta cualquier proyecto de promoción del emprendimiento, especialmente en el ámbito de la economía social, es el de la transformación y comercialización de sus productos ${ }^{56}$. Además, la comercialización vía internet también es complicada si tenemos en cuenta las dificultades de posicionamiento en los buscadores y la obligación de acudir a los grandes de la logística para hacer llegar los productos a los consumidores últimos.

En base a lo anterior, se consideró la posibilidad de desarrollar una plataforma de comercialización ${ }^{57}$ y una logística propia, que permitiesen la puesta en el mercado de los productos elaborados por los emprendedores sociales. Desde la primera fase de selección de cada proyecto de emprendimiento se identificarían las necesidades de una comercialización adecuada que se apoyaría fundamentalmente en el modelo diseñado para la Red de Emprendimiento y Desarrollo Local (REDL), cuyos objetivos serían:

- Comercializar productos del emprendimiento y el desarrollo local.

- Apoyar a emprendedores que no dispongan de un buen posicionamiento en Internet o tengan problemas de comercialización debido a un tamaño excesivamente pequeño o a productos ligados a una zona geográfica muy concreta (industria agroalimentaria ecológica, turismo sostenible...).

- Aprovechar la Economía de la larga cola, poniendo en el mercado productos cuya demanda local es muy reducida.

- Acceder a un segmento específico del mercado: consumidores con una conciencia de la necesidad de sostenibilidad, la defensa del medio ambiente y la potenciación de la artesanía y el medio rural.

56. Más aún si, como es este caso, las empresas se concentran en el sector agroalimentario y se sitúan en una pequeña población que, si bien tiene acceso a infraestructura de comunicación, no está muy próxima a núcleos urbanos (44 km a Ponferrada y $33 \mathrm{~km}$ a Astorga), lo que hace que la comercialización directa sea difícil.

57. Las características o criterios de la plataforma de comercialización serán: Adicional, no es la única vía de comercialización de las empresas. Colaborativa, colaboración con asociaciones de vecinos, instituciones organismos públicos y privados, etc. para crear una red de distribución. Extensiva, utilización de espacios variados para el depósito de productos. Creativa, aprovechamiento de las ventajas tecnológicas con la participación de INTECCA UNED. Logística social, utilización de diferentes alternativas de logística (dropshipping, empresas sociales de logística, creación de una empresa de logística propia, etc.). 


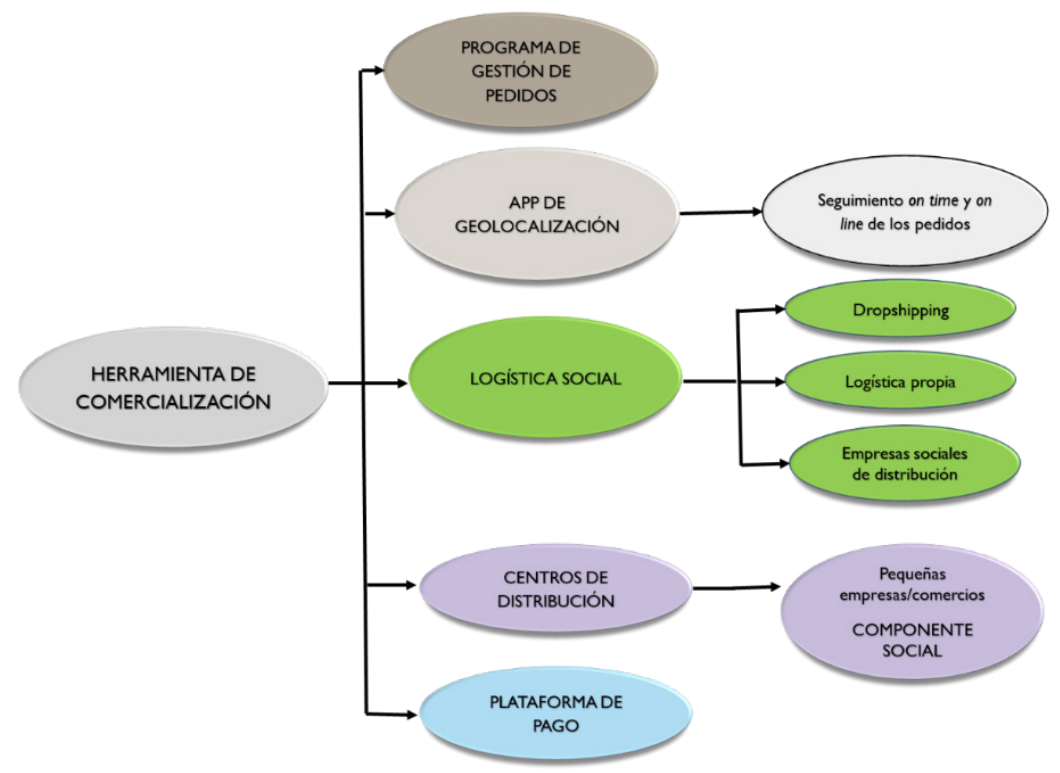

Figura n. ${ }^{\circ}$ 4. Esquema de la Herramienta de Comercialización de la Red.

Esta Red de Economía Social soportada en la Plataforma Tecnológica de la Red Nacional de Servicios de Formación, Información y Comunicación de la UNED, facilitaría el aumento de las conexiones entre usuarios generadores y receptores de bienes y servicios (enormidad); ampliaria la escala en la que comparten información y trabajo colaborativo (comunalidad); y, sobre todo, incrementaría su capacidad para crear vínculos sobre temas más particulares (la especificidad propia de los modelos de Larga Cola).

En definitiva, este proyecto de investigación tuvo como principal resultado la puesta en marcha de la Red Social de Personas Activas por la Economía Social "Cooperactivas" ${ }^{58}$.

Un resultado muy relevante a los efectos de este artículo es la adhesión a dicha Red de la Agrupación de Municipios Mineros de Castilla y León, constituida por los 31 municipios denominados grupo 1 en el Plan de Dinamización económica de los municipios mineros de Castilla y León 2016-202059.

58. https://cooperactivas.com/

59. El ámbito de actuación de este Plan se extiende a los 81 municipios incluidos en el Anexo del Real Decreto 1112/2007, de 24 de agosto, por el que se establece el régimen de ayudas al desarrollo de las infraestructuras en las comarcas mineras del carbón. 
Con este antecedente, y con el patrocinio de la Diputación de León, se está trabajando actualmente en el Proyecto Incuba ${ }^{60}$, que fomenta el emprendimiento desde el enfoque de puesta en valor de los recursos naturales y patrimoniales para lograr un territorio sostenible, y cuyo objetivo es la puesta en marcha de una red de emprendimiento social que ponga en valor los recursos naturales y patrimoniales, creando un producto transferible de buenas prácticas para el Turismo Sostenible y el Desarrollo Local en los ámbitos de la formación, la difusión, uso sostenible, investigación y puesta en valor del rico y singular patrimonio del espacio rural de la Provincia de León. Las actividades previstas en el Proyecto ${ }^{61}$ abordan las principales problemáticas y carencias sobre el conocimiento de los recursos Naturales y Patrimoniales en el Medio Rural de la Provincia de León y su gestión, sobre un enfoque de emprendimiento social sostenible. A ello se suma la necesidad de desarrollar planes especiales e instrumentos de planeamiento para la puesta en valor de los recursos naturales y patrimoniales que, a la vez, son esenciales para permitir el desarrollo económico de los núcleos de población. Las acciones propuestas en el proyecto pretenden realizar intervenciones armónicas con los planes vigentes en las políticas europeas, nacionales y autonómicas de Patrimonio Natural, Cultural y Turismo, contribuyendo a la recuperación y creación de espacios y productos que como los que se pretende desarrollar, vertebren los valores comunes de tipo natural, histórico y cultural con una proyección general hacia el ámbito turístico sostenible ${ }^{62}$.

El Proyecto generará, aparte de la formación de los participantes y de los habitantes del espacio, un aumento de sus competencias como emprendedores sociales, el afloramiento de nuevos recursos visitables que complementen la oferta turística y la diseminación de buenas prácticas y resultados dentro y fuera del espacio rural de la Provincia de León. Además, los resultados contribuirán a impulsar el emprendimiento local y las estrategias de comunicación, creando un ejemplo territorial modélico y extensible que vincule al territorio de la Provincia de León a equipos de investigación con carácter estable, convirtiéndose en un potencial recurso.

Un objetivo clave del proyecto es crear una Incubadora de emprendimiento social para promover la creación de un tejido de actividades económicas con los siguientes objetivos específicos:

60. http://catedraturismosostenible.es/incuba/

61. Actividades a desarrollar durante las anualidades 2020, 2021 y 2022: Investigación, desarrollo e innovación basados en el enfoque de economía circular; fomento del emprendimiento; turismo sostenible; plan de marketing-marca; plataforma de comercialización y plan de formación.

62. Como expresa la Carta de Bruselas, «el Patrimonio Cultural es un valioso e insustituible recurso como elemento revitalizador de las ciudades, las poblaciones y los territorios, capaz de mejorar de vida de los habitantes y de catalizar las inversiones, siendo especialmente necesario para el desarrollo de territorios periféricos y afectados por procesos de despoblación». 
JORGE VEGA NÚÑEZ Y JOSÉ LUIS CALVO GONZÁLEZ

EL OBSERVATORIO DEL NOROESTE IBÉRICO: EMPRENDIMIENTO SOCIAL PARA UN TERRITORIO SOSTENIBLE

- Evitar la despoblación consolidando actividades económicas y generando puestos de trabajo.

- Establecer un modelo económico sostenible que abandone el actual paradigma del modelo económico lineal e instaure un modelo de Economía Circular que a través del aprovechamiento de los recursos prime la reducción, la reutilización y el reciclaje, siendo respetuoso con el medio ambiente y que fomente el desarrollo local.

- Fomentar el emprendimiento social como alternativa para el desarrollo profesional bajo otras formas de emprender y de hacer empresa, ligadas a la economía social y solidaria con un impacto en el entorno (social, ambiental y económico) positivo para el conjunto de la sociedad.

- Fomentar el trabajo en red, aprovechando recursos e infraestructuras existentes en los Municipios implicados en el proyecto.

- Generar sinergias entre las actividades de los/as socios/as y participantes del proyecto que les dé un impulso inicial en la actividad.

- Por último, la Creación de un "Mercado Social Leonés», la Gestión de Marketing y el apoyo a la comercialización de los productos bajo marcas específicas con carácter territorial.

En la gestación del proyecto se ha llevado a cabo una intensa labor de colaboración con todos los potenciales agentes participantes tanto públicos como privados, que ha tenido como resultado fundamental el "consenso" respecto al modelo de gestión participativa que ha de gobernar el proceso de fomento de emprendimiento que contribuya a la reactivación del territorio rural de la provincia de León.

Un aspecto clave de este modelo participativo consiste en la constitución de un comité de gestión de proyectos que descansará en "Mesas de Trabajo» encargadas de coordinar, generar feedback, mostrar los resultados a evaluar y consensuar los mejores proyectos de cara al objetivo definido.

En definitiva, se trata de aplicar los ya comentados Principios de actuación del Modelo de Gobernanza del Observatorio Territorial del Noroeste, Diplomacia, Colaboración, Corresponsabilidad y Transparencia; además de aplicar una "estrategia bottom-up» que favorezca la implicación de todos los actores clave del territorio para llevar a la práctica el modelo consensuado. 


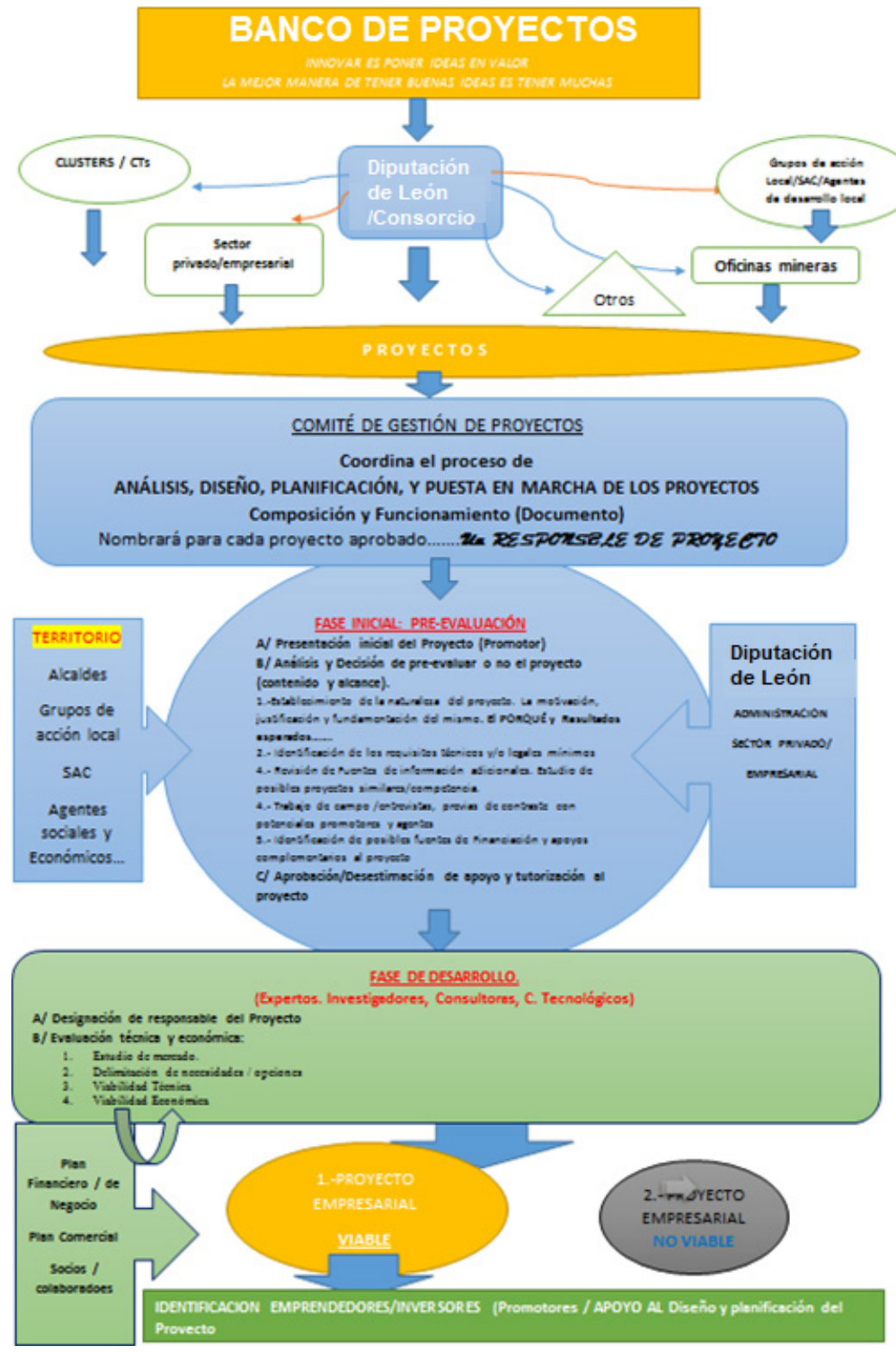

Figura n. ${ }^{\circ}$ 5. Modelo de gestión participativa que gobernará el proceso de emprendimiento. 


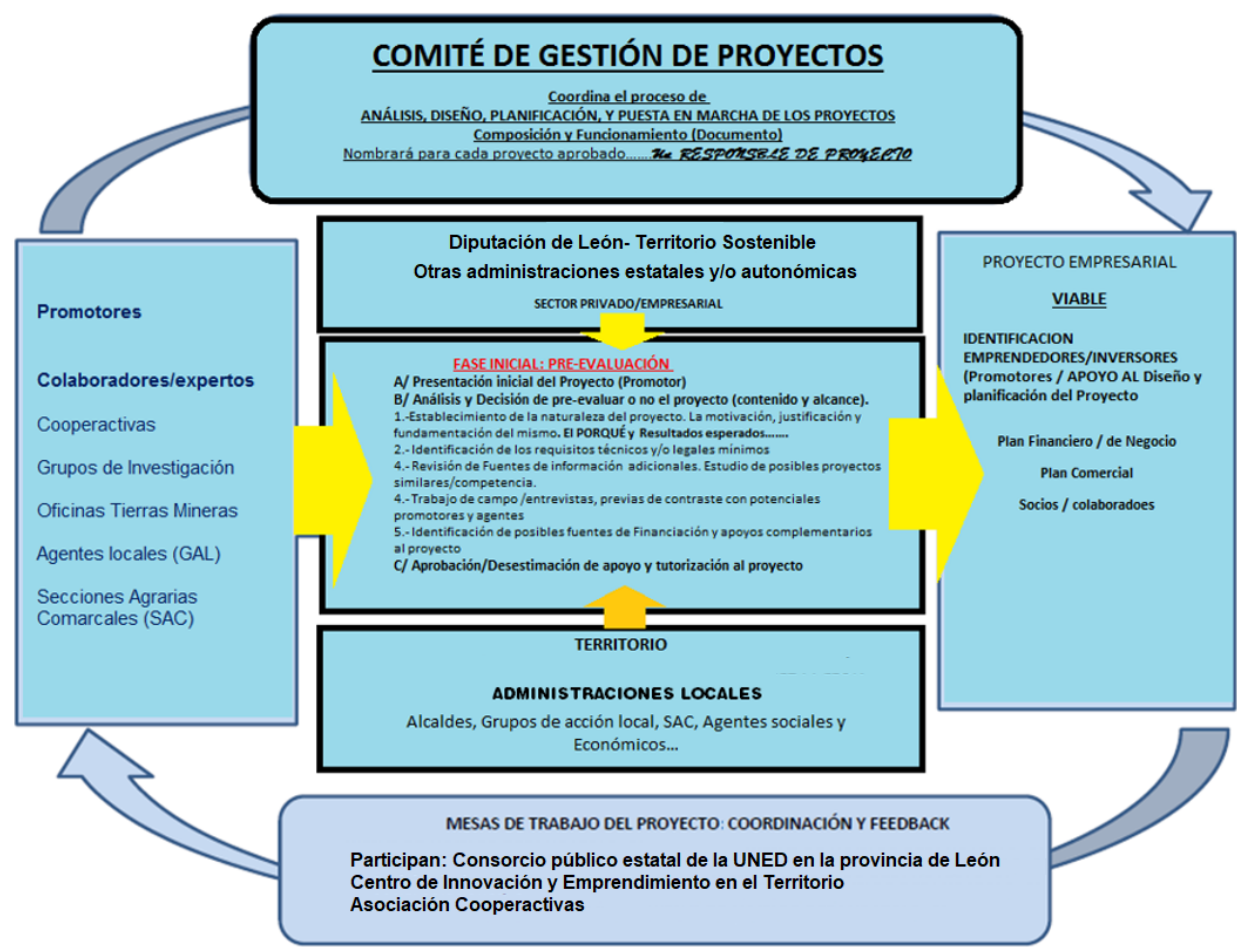

Figura n. ${ }^{\circ}$ 6. Comité de gestión de proyectos de emprendimiento y desarrollo local.

Por lo tanto, estará muy presente la participación, la cooperación local, y la generación de sinergias dentro del territorio de actuación, de forma que todas las fases del proyecto $^{63}$ se desarrollarán buscando aprovechar y mejorar todos los recursos existentes en cada una de las zonas rurales de la provincia. Todo ello utilizando el enfoque de la sostenibilidad, el desarrollo local y la economía circular como eje transversal que debe servir de catalizador a todo el proceso de reactivación socioeconómica del territorio.

Otro aspecto relevante a la hora de impulsar esta Red Social para un territorio sostenible consiste en considerar el importante papel que la mujer juega en el desarrollo local. En este sentido, comentábamos en la introducción del presente trabajo que el modelo socioeconómico que debe consensuarse con el objetivo

63. Las fases del proyecto de la incubadora serán: Diseño y creación de Equipo; Sensibilización y Comunicación; Prospección de emprendedores/as sociales y de expertos y entidades colaboradoras en el territorio y Puesta en marcha. 
JORGE VEGA NÚÑEZ Y JOSÉ LUIS CALVO GONZÁLEZ

de reactivar el territorio, como primera condición, debía ser compatible con los Objetivos de Desarrollo Sostenible de la ONU ${ }^{64}$.

En esta línea, nuestra Universidad ha creado un Observatorio ODS y, en ese marco, desde la Cátedra de Turismo Sostenible y Desarrollo Local se ha puesto en marcha un Observatorio de Desarrollo Local Sostenible e Igualdad de Género ${ }^{65}$ que viene desarrollando un conjunto de actividades que ponen de relieve el papel de la mujer en el desarrollo territorial ${ }^{66}$. El objetivo general de todas estas acciones es promover la igualdad de oportunidades a través del desarrollo de medidas que favorezcan el incremento de la presencia y la participación activa de la mujer en todos los ámbitos de la vida social, incentivando el desarrollo rural mediante la participación y emprendimiento con perspectiva de género. También se trata de dotar a los participantes de las herramientas para poder poner en marcha un proyecto de desarrollo rural, desde la perspectiva de género. Se ha dado la posibilidad de reflexionar y aprender por qué no vivimos en el entorno que libremente queremos vivir, cuando se trata de vivir en nuestros pueblos, así como crear redes para asentamiento de población y el desarrollo sostenible. Se han puesto de manifiesto las opciones de vida de la mujer en el mundo rural y las claves para generar un cambio hacia una economía social y transformadora.

Por último, con todos estos antecedentes, en el mes de febrero de 2020 y bajo el liderazgo del Ayuntamiento de Ponferrada, se logra un relevante resultado con la puesta en marcha de un Centro de Innovación y Emprendimiento en el Territorio ${ }^{67}$ que, con el soporte imprescindible de la Catedra de Turismo Sostenible y Desarrollo Local y del Centro Tecnológico INTECCA, pretende consolidarse como polo tecnológico en el ámbito de la inteligencia artificial, las tecnologías semánticas y el internet de las cosas. Planteamiento que, alineado con la estrategia europea de datos, está promoviendo un vivero de emprendimiento de base tecnológica que ha de complementar y potenciar la red social para el territorio sostenible analizada en el presente trabajo.

64. La Asamblea General de la Organización de las Naciones Unidas (ONU) adoptó en el año 2015 la Agenda 2030 para el Desarrollo Sostenible, un plan de acción a favor de las personas, el planeta y la prosperidad, que también tiene la intención de fortalecer la paz universal y el acceso a la justicia.

65. http://catedraturismosostenible.es/oigdl/

66. Las principales acciones desarrolladas hasta la fecha incluyen: Congreso científico divulgativo: Igualdad de género: hacia una nueva construcción social; Jornadas Observatorio de Igualdad de género y desarrollo local sostenible; Curso Mujer: la clave del desarrollo rural; Jornadas Itinerantes. Mujer: La clave del desarrollo rural en colaboración con la Diputación de León y Curso Mujer, la clave del Desarrollo Rural: análisis socioeducativo.

67. http://catedraturismosostenible.es/centroinnovacion/ 
JORGE VEGA NÚÑEZ Y JOSÉ LUIS CALVO GONZÁLEZ

EL OBSERVATORIO DEL NOROESTE IBÉRICO: EMPRENDIMIENTO SOCIAL PARA UN TERRITORIO SOSTENIBLE

\section{CONCLUSIONES}

En este artículo nos hemos planteado un reto y una hipótesis: el reto, la reactivación de territorios desequilibrados económicamente y en vía de despoblamiento (popularmente conocidos por España vacía o vaciada); la hipótesis, que para superarlo con éxito se requiere un ecosistema de colaboración e innovación que, primero consensue un modelo socioeconómico adecuado para la reactivación del territorio concreto del que estamos hablando, y, segundo lo desarrolle en la práctica en base al fomento de un emprendimiento social que sea capaz de aprovechar las inmensas posibilidades tecnológicas del actual paradigma económico.

De esta forma, hemos descrito como el Observatorio Territorial del Noroeste ha venido generando actividades basadas en el conocimiento que, centradas en la innovación y las nuevas tecnologías, han contribuido a crear servicios de valor en el territorio.

Sobre la base de la participación, los agentes sociales, económicos, ambientales y políticos de la Comarca de El Bierzo como laboratorio del Noroeste vienen colaborando en una Red de Emprendimiento Social que trata de lograr un territorio más sostenible. Esta Red de Economía Social soportada en la Plataforma Tecnológica de la Red Nacional de Servicios de Formación, Información y Comunicación de la UNED, facilita el aumento de las conexiones entre usuarios generadores y receptores de bienes y servicios (enormidad); amplia la escala en la que comparten información y trabajo colaborativo (comunalidad); y, sobre todo, incrementa su capacidad para crear vínculos sobre temas más particulares (la especificidad propia de los modelos de Larga Cola).

En el momento actual, caracterizado por una crisis sanitaria y socioeconómica sin precedentes, esta es una línea de trabajo estratégica con la que nuestra Universidad está contribuyendo de forma destacada al desarrollo local, en especial, en la reactivación de territorios desequilibrados económicamente y en vías de despoblamiento, que como ocurre en la provincia de León, están especialmente necesitados de este tipo de actuaciones.

\section{REFERENCIAS BIBLIOGRÁFICAS}

Adorno, T., Horkheimer, M. (1944-1947) (1988). La industria cultural. Iluminismo como mistificación de masas. En Dialéctica del iluminismo. Buenos Aires: Edit. Sudamericana.

Anderson, C. (2006). La economía Long Tail. Barcelona: Ediciones Urano.

Anderson, C. (2014). Makers: The New Industrial Revolution. Crown Business.

Antonescu, D. (2014). Theoretical Approaches of Regional Development, Institute of National Economy, Munich Personal RePEc Archive (MPRA), paper 60524.

https://mpra.ub.uni-muenchen.de/60524/

Banco Mundial. (2004). Local Development Discussion Paper, prepared for the International Conference on Local Development, Washington DC, 16-18 june. 
JORGE VEGA NÚÑEZ Y JOSÉ LUIS CALVO GONZÁLEZ

EL OBSERVATORIO DEL NOROESTE IBÉRICO: EMPRENDIMIENTO SOCIAL PARA UN TERRITORIO SOSTENIBLE

Barozet, E. (2003). El aporte del análisis de redes sociales a los temas de gobernanza en sistemas complejos: de la red a los policy networks. Revista de Estudios Avanzados, pp. 1-13.

Boisier, S. (1999). Desarrollo (Local): ¿De qué estamos hablando?, Documento comisionado por la Cámara de Comercio de Manizales, Colombia.

Caves, R. E. (2000). Creative Industries: Contracts between Art and Commerce. Universidad de Harvard.

Coase, R. (1960). The problem of social cost. Journal of Law and Economics, 3, pp. 1-44.

Coffey, W., Polèse, M. (1984). The Concept of Local Development: A Stages Model of Endogenous Regional Growth, Papers of the Regional Science Association, 55(1), pp. 1-12.

Gedda, D., Nilsson, B., Sathen, Z., \& Solberg Soilen, K. (2016). Crowdfunding: Finding the Optimal Platform for Funders and Entrepreneurs", Technology Innovation Management Review, 6(3), pp. 31-40. https://timreview.ca/article/973.

Giones, F., Oo, P. (2017). How Crowdsourcing and Crowdfunding are Redefining Innovation Management, en A. Brem, E. Viardot (Eds.), Revolution of Innovation Management: 43-70. London: Palgrave Macmillan UK. https://doi.org/10.1057/978-1-137-57475-6_3

Hall, C. M. (2000). Rethinking collaboration and partnership: A public policy perspective. Tourism collaboration and partnerships: Politics, practice and sustainability, 2, pp. 143-158.

Powell, W., Snellman, K. (2004). The Knowledge Economy. Annual Review of Sociology, 30(1), 199-220.

Rodrigo, C., Ruiperez,A., Martínez, D., Sernández, A. y Vega, J. (2009). Hacia una Red Nacional de Servicios de Formación. Información y Comunicación en la UNED. Boletín de RedIRIS, 85-86, pp. 67-74. https://www.rediris.es/difusion/publicaciones/boletin/85-86/ponencias85-9.pdf

Santos, B., Da Sousa. (2003). Desigualdad, Exclusión y Globalización. La caída del angelus novus: ensayos para una nueva teoría social y una nueva práctica política, Bogotá: ILSA, pp. 125-165.

Stoker, G. (1988). The politics of local government. Oxford: MacMillan.

Vázquez Barquero, A. (2009).Desarrollo Local, una Estrategia para Tiempos de Crisis. Universitas Forum, 1(2), pp. 1-11.

Vega, J., Calvo, J. L., Lorenzo, M. J., Osuna, R. (2011). Microeconomía Del Turismo. Madrid: Editorial Sanz y Torres.

Vega, J. (2010). Innovación Tecnológica Aplicada al Espacio Europeo de Educación Superior: La herramienta docente audiovisual sobre tecnología IP (AVIP). Una Red Nacional de servicios de Formación, Información y Comunicación. (Tesis Doctoral).UNED, Madrid.

Vega, J., Calvo, J. L. (2016). Microeconomía. Teoría y Realidad. Madrid: Editorial Dykinson.

Vega, J., del Fresno, M., Marqués, P., Paunero, D. et al. (2014). Conectados por Redes Sociales. Introducción al Análisis de Redes Sociales y Casos Prácticos. Barcelona: Editorial UOC. 
